\title{
Project Management Trends and New Challenges 2020+
}

\author{
John McGRATH 1,* and Jana KOSTALOVA ${ }^{2}$ \\ 1 Technological University Dublin, Dublin, Ireland; John.Mcgrath@TUDublin.ie \\ 2 University of Pardubice, Pardubice, Czech Republic; jana.kostalova@upce.cz \\ * Correspondence: John.Mcgrath@TUDublin.ie
}

\begin{abstract}
This study explores how the discipline of project management is currently approached within organizations and examines how the discipline will need to adapt to remain relevant in an era of constant change and the growth in project-based organizations. The data for this qualitative research study was collected from project management experts who participated in panel discussions at a conference held on 7th of November 2019 in Dublin, Ireland (The PMO Road Show - International Project Management Day). This study is also based on a literature review of project management trends presented in the last three years. Results suggested that in the technology driven world of the future, project managers will require a different set of skills. The study found there is also a significant increase in more successful project outcomes when project teams develop more bespoke hybrid mythologies tailored to unique project environments.
\end{abstract}

Keywords: project management; project management trends; sustainable project management; project teams; project management competences; project management maturity

\section{JEL Classification: O32; M19}

\section{Introduction}

Project management is continually evolving and will continue to gain momentum as a strategic competency and critical business discipline across all industry sectors. Organizations are increasingly adopting a project-based approach and there is no indication that this trajectory will waiver or lose momentum in the next decade. Project based work is now business as usual for many traditional business units. The world of work has changed and so to must the discipline of project management. In times of social, environmental, economic and increasing technological changes, project management must evolve and adapt to changing conditions if it is to remain relevant and meet the evolving demands of future focused organizations.

In technological development the changes are driven by the 4th industry revolution or Industry 4.0. Changes include automation, digitalization, integration, robotization, artificial intelligence and machine learning, cyber-physic systems, analysis of big data via business intelligence, wide range of internet usage - internet of things, internet of services, internet of people, augmented reality, virtual reality, 3D printing, blockchain, etc. (Marik et al. 2016). Society is changing and organizations are being forced to reinvent their business model to adapt to an hyperconnected global economic environment intwined with a shared/collaborative economy.

Corporate Social Responsibility (CSR), Climate Change and Sustainability has taken center stage as customers seek to reduce their carbon footprint and become responsible environmental citizens. This has impacted on every aspect of social, economic and political life, including approaches to delivering projects. Project Management Offices (PMO's) therefore must consider energy needs and propose sustainable solutions across the business landscape from production to processes based activities.

In the approaching years and decades, it is likely that we will witness significant changes in the area of how and where people work, how task management is approached and the very essence of the discipline of work. Technology, artificial intelligence and robotics will undoubtedly result in a fundamental shift in the role of humans in organizations and project teams. We are in the midst of a transformation to globally dispersed diverse remote project teams and an increasing organizational focus 
on knowledge, training, competency, flexibility and the adaptability of people. These collective changes will have a transformational impact on how organizations approach the art and science of project management, the role of the project manager and the methodologies and frameworks deployed.

The aim of the article is to analyse the current trends and approaches that are emerging in the discipline of project management methodologies, to focus on future project management skills and capabilities and the research will present guidance on how individuals and organisations can adapt to the future project management landscape that will develop over the next 5 years.

In secondary literature resources have been identified and trends presented based on observations over the last 3 years:

- Impact of technological developments on project management;

- Requirement to implement sustainable practices into the discipline of project management;

- Tailored hybrid approaches based on traditional waterfall methodologies blended with agile and adaptable project management approaches tailored to unique project environments;

- Increasing demand for Project Managers but also increasing demands on the role of the project manager;

- Diverse globally dispersed project teams who work remotely;

- New requirements on project manager and team member skills;

- Project Management Office (PMO) as a Centers of Excellence for executing strategy.

\subsection{Technological development}

Technology is having an increasing impact on project management methods, tools and techniques and the very essence of project work. There are many aspects of project management that can benefit from new technological capabilities.

The first aspect is the digital transformation of project management approaches. This is not limited to just project documentation in electronic format but more about the digital transformation of the full project life cycle: initiation, planning, execution, monitoring and controlling and project closeout. Project focused technology tools also empower project teams in knowledge areas such as scheduling, risk, communications and cost management. Digitization also empowers project teams to innovate in approaches to project work. Digitisation also empowers organizations to harness data for data-driven strategic decision making. Based on digitized data it is possible to use other project management tools.

Project managers need to make accurate predictions and decisions regarding project status. Artificial Intelligence (AI) and Machine Learning will help in this area and provide project managers with relevant and timely information. Based on data analysis it is possible to analyze risks, predict problems before they arise which will empower project managers a competitive advantage. (Rastogi 2019)

Boogaard (2019) describes the areas of project management AI usage:

- Identifying potential risks through natural language search.

- Improving risk assessments.

- Testing risk response.

- Allocating resources and resource levelling.

- Intelligent scheduling.

- Automating mundane and repetitive tasks.

- Improving consistency in process and decision making.

Automation will be useful in project data collection but also in filtering and directing project communications by client, by stakeholder, by priority etc. Project payments, risk updates, daily or weekly check-in messages, reports, generating of alert in cases of variations in schedule, budget or risk assessment etc. (Aston 2019)

Middleton (2017) presented the results of research between JIRA project management software users. $39 \%$ of respondents confirmed to use some aspect of $\mathrm{AI}$ in their work, $87 \%$ of respondents expected changes in their work related to $\mathrm{AI}$ and $76 \%$ of respondents declare that some or half of their work could 
be covered by AI, robots, algorithm, devise etc. The development of AI usage is very dynamic and ever increasing.

Musienko (2019) presented as the most important benefit of AI in project management is the ability of task prioritizing and planning and optimal resource allocation based on the data analysis application to complex projects.

Mohan (2019) anticipates the extension of the application of AI and Internet of Things (IOT) especially in controlling projects remotely, benchmarking, setting realistic expectations and greater efficiency in fewer agile cycles. In a similar vein Dharmalingam (2018) identifies the Internet of Things (IOT) as a catalyst to the discipline of project management:

- It enables to provide a hyper speed reporting.

- It gives an overall process and monitoring control.

- It creates an explosion of highly valuable project data.

- Extremely deep data analytics is made easy by the use of internet of thinks.

- A comparatively stricter legal and ethical implications can be bought into the practice.

Kratky (2015) and Dharmalingam (2018) positively evaluated the usage of cloud-based project management systems in collecting of real-time data, in sharing of data, in communication, etc. Technological development extends the tools of remote communication (Kratky 2015).

As the use of technological tools increases, it is necessary to increase the level of cybersecurity. In this domain Dharmalingam (2018) anticipates the next steps lie in advancing the formal regulation to set a standard of detection, prevention, and response from technology.

\subsection{Sustainability in project management}

There is an increasing swell from society demanding a more environmentally responsible approach in all project activities, there is increasing pressure to include a sustainable element in project management approaches (Silvius et al. 2012). A body of research has presented the different approaches on how to include the sustainability element in project management methodologies, processes, planning and implementation.

Silvius et al. (2012) present the contrast between the projects and concept of sustainable development. From their point of view projects are short term oriented, the sustainable attitude is long term oriented, the projects are results oriented, the sustainable development is oriented on the whole life cycle of some economic activity, the main partner of projects is their sponsor, for sustainable development the most important stakeholders are current and future generations.

Implementation of sustainability in project management is not limited to changes in project management methods and tools. The focus is more so on a holistic approach to sustainability in changing project-oriented organization's top management attitude (Misopoulos et al. 2018) and change of the project culture in organization (Zheng et al. 2017).

Silvius et al. (2012) recommend the implementation of six key sustainability principles into a project management methodology:

- Sustainability is about balancing or harmonizing social, environmental and economic interests in contrast to project management which is oriented on triple constraint balancing (time, cost, scope of project).

- Sustainability is about both long-term and short-term orientation in contrast to project management which has a temporary orientation limited to the life of the project.

- Sustainability is about local and global orientation, just as is project management with remote team members and worldwide suppliers. The evaluation of the most sustainable solution: the solution with the lowest impact on the environment (local or global) has to be incorporated into the project management approach.

- Sustainability is about the consumption of resources, not capital, what is interpreted in project management in the sophisticated way of resource selection and usage. 
- Sustainability is about transparency and accountability, the governance rules which are applied in project management, the future trend is the increase of the transparency presentation towards the wider group of stakeholders.

- Sustainability is about personal values and ethics the rule which is an important part of international project management standards, in sustainable attitude it is strengthened and expanded.

Chofreh et al. (2019) analyzed the research areas of sustainable project management and present the anticipated areas of future sustainable project management research.

\subsection{Tailored approaches based on available project management methodologies and based on the project specifics}

An important change associated with increasing demands in the ability to manage changes in project management was the introduction of agile project management and its implementation in practice. This trend of continually adapting to and managing constant change in project scope or success criteria and flexibility in the context of a rapidly changing and evolving world brings the trend of not adhering to strictly international project management standards or other methodologies, but to create a bespoke hybrid project management methodology that is tailored to the unique project environment. Project managers in this environment will also be required to be more flexible, deploying critical thinking skills and professional judgment more than ever before (Boogaard 2019).

Aston (2019) defined this trend as method melding, he recommends using traditional waterfall project management, agile project management and other project management methodologies as open project management umbrella and use them in accordance with specifics of the organization. Aston (2019) also mentioned trend to use agile project management in more and more areas not only in software development.

Musienko (2019) recommended the blending of different project management approaches, to use methods and tools from other management areas like Kanban. Brownlee (2019) summarizes this trend under a title Hybrid Project Management Approaches and Methodologies.

On the one hand, this approach expands the application of project management to wider organizational challenges, however on the other hand, this also increases the demand and requirements for more complex project management skills (see chapter 1.6.).

\subsection{Increasing demand for project managers}

Surveys confirm the increasing trend in the number of project management roles and job opportunities. Project management Institute (2017) presented a dramatic increase in the number of jobs requiring project-oriented skills mainly in emerging economics like China and India and the extension of project management approaches in not typically project oriented sectors such as health care, finance and insurance and services. Their previous survey from the year 2012 estimate the number of projectoriented jobs by 2020 would be number 52.4 million. By early 2017, the number of project management jobs had reached 66 million. By 2027 the Project Management Institute (2017) estimate 87.7 million of project-oriented jobs.

With the trend of increasing project management roles, we are also witnessing another trend in the changing way project managers and project team members conduct project activities. This is intertwined with the trend of freelancing and the increase in the gig economy.

Gig economy indicates a limited area of collaborative economy or shared economy, where the shared subject is work. Gig economy favors the acquisition of work performance on the basis of temporary flexible contract delivery, where the work of the contractor, the freelancer, is preferred to the permanent employee (Schroeder 2019; Chappelow 2019). Gig economy is also characterized by performing work at any location thanks to a remote connection (Rose 2016). Deliveries of work within the shared economy are also referred to as freelance economy (Rinne 20017; Görög 2018).

Stats from the Bureau of Labor Statistics show that 1 in 3 workers earns income from non-traditional, non-9-to-5 employment. In fact, in a recent World Economic Forum's Report, almost half (44\%) of 
respondents rated "changing work environments and flexible working arrangements" as the top socioeconomic driver of change (Aston 2019).

In 2015 Newman and Williams (2015) forecasted the increase of the number of project managers in the position of "mobile project managers" - working on a number of short-term contracts. It was the prediction of development of project teams till 2020. This change is closely connected also with the technological development in area of communication tools and creation of virtual/remote project teams (Mohan 2019). Project Management Institute (2019) confirm this trend, based on their worldwide survey with 5,402 project management professional respondents that analyzed 2018 situation, 68\% of organization outsourced or contract project managers.

This change of organization of the work will bring many advantages like reduction of costs to project solvers, organization of jobs activities in the wellbeing mode for employees or more exactly freelancers. On the other hand, the project managers or team members employed on contract-based agreement will be more responsible to find new contracts.

\subsection{Diversed project teams involving remote members}

Analysis in area of human resource management confirm that workplaces will continue to become more and more diverse in the coming years. Arguably, factors like changing parental roles, shifting policies and attitudes regarding sexual orientation/gender identity, increasing globalization, and an aging workforce will result in increasingly diverse project teams. Teams of tomorrow will have increasingly varied types of workers (including full time, part time, contractor/freelance, remote, etc.) potentially complicating administrative operations, day to day communications and team dynamics. (Brownlee 2019). Loehken (2014) confirms that heterogeneous teams are widely used in the work activities and projects. The team consists of men and women, representatives of older and younger generations (generation $Z$, millennials, generation $X$, generation $Y$, baby boomers), especially in international companies there are team members of different nationalities and cultures. Loehken (2014) positively evaluates mainly ability of diverse team to approach the solution creatively and evaluate more diverse designs increases as opposed to homogenous teams.

Thanks to technological development and virtual communication platforms the project team members from different locations in the world can be a member of project teams, Rastogi (2019) expects the explosion of remote project team members and project managers after 2019. It brings the reduction of administrative costs, travel and logistic costs etc.; on the other hand there is more complication organization of work because team members are not office based, the could work in remote form from home, from abroad in the same time zone or different time zones, or project team members could be work nomads (Musienko 2019). Mainly young generation (millennials and Z generation) is shifting from facetime hours to working in flexible regime and remotely (Mohan 2019).

For successful management of diverse teams, project managers have to increase their knowledge of diversity management so that all members will be involved in the project and can contribute to its implementation with maximum use of their capabilities. (Betchoo 2015; Sayers 2017).

\subsection{New requirements on project manager and team member skills}

In addition to knowledge in diversity management there is systematic pressure on increase the project manager and project team member knowledge in all areas - hard project management skills, soft skills and skills in related areas like information and communication technologies (ICT) (Musienko 2019; Brownlee 2019). Brownlee (2019) expects the requirement of knowledge of ICT like AI, data analysis, design thinking, automation, robotics, machine learning, security of ICT etc.) On the other hand, the spectrum of project management knowledge will be more complex and interconnected with other scientific areas (psychology, sociology, pedagogy etc.) and based on creativity, emotional intelligence and organizational skills (Rastogi 2019; Aston 2019).

Newman and Nigel (2015) expect the increase of project management certification as tool to unify approaches in project management methodology and standardize the project management terminology in diverse/remote teams. Duncan (2019) presented that worldwide 50,000 individuals declare the level of their knowledge by competence-based certification and other 450,000 declare knowledge-based 
credentials. There are available certifications of three the most important project management methodologies (Project Management Institute, International Project Management Association, and Project IN Controlled Environment - PRINCE2). Such certifications of project managers and project team members in different methodologies and other form of training (on-line courses, e-learning, webinars, gamification etc.) bring the improvement of project management maturity and could bring the opportunity to create the system of project management based on specific conditions on organizational level, and based on different type of project. (Musienko 2019; Dharmalingam 2018; Boogaard 2019).

Project Management Institute (2019) present the new role of project managers, based on their survey of 5,402 project management professional respondents:

- Strategic advisor - project managers help with planning, execution projects in portfolio in accordance to strategy of the company.

- Innovator - project managers act as product owners and developers.

- Communicator - project managers have the ability to lead people and communicate clearly, no matter the audience.

- Big thinker - project managers are flexible, adaptable and emotionally intelligent.

- Versatile manager - project managers have experience with different approaches - waterfall, agile, lean, design thinking, etc. and are able to apply it in hybrid approach.

\subsection{Project management offices and Centres of Excellence}

Project management office (PMO) is a standard part of project management infrastructure in most organizations. Project Management Institute (2019) in their worldwide survey of 5,402 respondents, that analyzed year 2018 situation, presented $82 \%$ of organization has got PMO, and $72 \%$ of them indicate there is high alignment of the PMO to organizational strategy.

The role of PMO is changing from administrative support, creator of project management methodology rules and controller of project portfolio to Centre of Excellence. The Centre of Excellence is responsible for devising the strategic roadmap consisting of business models and processes that'll help the organization prosper in the future. It identifies strengths and weaknesses and develops competencies to mobilize and leverage true potential into the right opportunities. A Centre of Excellence also assesses firm's risk and channels their expertise into business activities, resources and capabilities needed to drive projects forward (Mohan 2019).

These have the innate ability to bridge the gap between the effective implementation of the project and the organization's high-level strategic prescience. And due to this robust reason, the PMOs and/or Centers of Excellence have been seen gaining more popularity in the recent future project management trends 2019 (Dharmalingam 2018). These ability of PMO is supported by top management level and also by improvement of project management information systems.

Boogaard (2019) highlights other role of PMO in time of insufficient project managers and team member skills. Less experienced project managers and project team members are going to be learning more heavily on PMO by their experienced colleagues, so mentoring, coaching and other way of knowledge transport are intensively used.

Project Management Institute (2019) and Musienko (2019) confirm another emerging trend in PMOs: intensive communication with project sponsors, to create more strategic relationships with sponsors. The sponsor must be involved into the project and should be interested not only in income and measurement of Return of Investment but must also be interested in the benefits of the project itself.

\section{Methodology}

First the scientific questions were specified - what are the expected trends in area of project management for next 5 years; what are the emerging challenges in this discipline; what can impact in a positive or negative way on the future development of project management? Based on the primary and secondary resources the trends of project management for next years are summarized. As secondary resource the literary review of in scientific papers, published surveys, web discussions and opinions of project management experts and project management associations or consultancy agencies presented via public information resources was done. As primary resources were used the results of 
panel discussion of project management experts on conference held on $7^{\text {th }}$ of November 2019 in Dublin, Ireland (The PMO Road Show - International Project Management Day). Based of analysis of summarized information the results and recommendation were specified.

\section{Results}

Project management experts have confirmed the above trends from their practice or experience and agreed on the further direction of project management towards:

1. Globalization, Industry 4.0, Digital Transformation and hyper-competition has changed the world view for most project environments. Projects also no longer exist in a vacuum and projects are now the execution vehicle in the formulation of corporate strategy and lift an organisation in terms of their competitive positioning in the global marketplace.

2. High performing organizations acknowledge Project management has evolved from the solving of technical problems to the enablers of change and organizational transformation. Organizations can no longer approach project management with the approach applied in previous decades. Projects are the new normal and therefore project management can no longer be seen as merely about functional project management or interlinking systems and processes, but more about faster, empowered, focused execution of strategy.

3. Successful project execution requires project teams to develop a network of building block to construct more agile, responsive approaches to achieving successful project outcomes. Senior Leadership teams should aim to build bridges and mend gaps between strategic planning and execution. Traditional corporate structure result in a lack of autonomy for project teams to make key strategic decisions. Despite aspirations of organizational agility, project teams are suffocating in levels of bureaucracy making empowerment, focus and agility almost an impossibility.

4. There is a need for a more bespoke approach than the generic frameworks allow. The project management capabilities required will vary from organisation to organisation, across industry sectors and size and scale of project.

5. New technologies available enable project managers to effectively manage a project from anywhere on the planet without a single face to face meetings with the team. There is also a whole new dynamic complexity of megatrends added to the mix: Globalization, AI, Automation, Virtual Teams, Digital Transformation, Diversity of Workforce, Gig Economy and changing corporate culture.

\section{Recommendation}

In today's era successful project managers must have the ability to demonstrate the unbiased fairness of a judge, the skills of a diplomat, the authority of a general and the understanding of a parent (McNamara 2003). Becoming "project savvy" is no longer a luxury: it is rapidly becoming a necessity (Pinto 2007). This has driven an increased need for project management techniques and a more advanced set of project management capabilities. This has been supported by Rahman, Shafique, and Rashid (2018) who states that organizations are now entering the era of competitive pressures in globalized and international markets.

The ability to quickly react to change has become paramount to the success of an organisation. Projects have become the catalysts by which organizations achieve these strategies, and the ability to manage projects effectively has become a required competency.

Project management is experiencing a fundamental shift. The traditional skills of project management: delivering to schedule, budget and are no longer enough in the new world of constant change. Organizations are looking for a new skillset and competency: somebody who can drive organizational change and lead transform within the organisation.

Organizations should nurture a holistic approach to developing a collaborative environment of selforganizing teams, empowered decision-making and strong leadership rather than strict authority. Organizations should equally strive to develop competencies and capabilities which are more agile, empowered, adaptable within the organisation. 
Project success contributes to organisation success and this has led to a fundamental shift in focus from tools, techniques and processes to consideration of skills such as creativity and innovation. While success of project management practices had commonly been attributed to the combination of tools, techniques and processes employed, more recent thinking has considered skills such as creativity, innovation as well as faster decision making by empowered teams to be the source of success.

To succeed in this new era, a high performing project team is required but this can't happen without project leadership. Project leaders must foster and environment where teams can achieve their full potential and overcome project challenges. Those challenges must create opportunities for the individual, the team and the organisation essentially a win-win for all.

\section{Conclusions}

On one hand, project management trends are driven by business trends, on the other hand the project management can bring a creative, innovative problem-solving approach to organizational challenges. Notwithstanding all organizational challenges are unique or at least different and therefore a broad-brush solution will simply not work. Success lies in a more bespoke project management methodology tailored in accordance with the project type, organisation culture and industry sector.

We are now in the era where all mature organizations recognize that all strategic change happens through projects and programmes. The next generation of project managers will need to develop a portfolio of skills to match not only the current but the future needs of the organisation.

To succeed in this new era, a high performing project team is required but this can't happen without project leadership. Project leaders must foster and environment where teams can achieve their full potential and overcome project challenges. Those challenges must create opportunities for the individual, the team and the organisation essentially a win-win for all.

\section{References}

Aston Ben. 2019. Prepare for These 7 Project Management Trends Transforming the PM Role. Available online: https:/www.thedigitalprojectmanager.com/project-management-trends-2019/ (accessed on 5 November 2019).

Betchoo Nirmal Kumar. 2015. Managing Workplace Diversity: A Contemporary Context. bookboon.com.

Boogaard Kat. 2019. Project Management Trends and Predictions for 2019. Available online: https:/www.goskills.com/Project-Management/Articles/Project-management-trends-predictions-2019 (accessed on 5 November 2019).

Brownlee Dana. 2019. 4 Project Management Trends On The Horizon...Are You Ready? Available online: https://www.forbes.com/sites/danabrownlee/2019/07/21/4-project-management-trends-on-the-horizonareyou-ready/\#23c3db976769 (accessed on 5 November 2019).

Chappelow Jim. 2019. Gig Economy. Available online: https://www.investopedia.com/terms/g/gig-economy.asp (accessed on 5 October 2019).

Chofreh Abdoul Mohammad Gholamzadeh, Goni Feybi Ariani, Malik Muhammad Noman, Khan Huma Hayat, Klemes, and Jiri Jaromir. 2019. The imperative and research directions of sustainable project management. Journal of Cleaner Production: 238, 117810. https://doi.org/10.1016/j.jclepro.2019.117810.

Dharmalingam N. 2018. Latest Project Management Trends in 2019. Available online: https://www.whizlabs.com/blog/project-management-trends/ (accessed on 7 November 2019).

Duncan William R. 2019. Project Management in the Year 2020. Available online: https://pmqlinkedin.wordpress.com/about/project-management-in-the-year-2020/ (accessed on 15 October 2019).

Görög Georgina. 2018. The Definitions of Sharing Economy: A Systematic Literature Review. Management: 13(2), 175-189. https://doi.org/10.26493/1854-4231.13.175-189.

Kratky Jiri. 2015. Proč je nutné umět ve 21. století řídit projekty? Available online: https://www.upce.cz/sites/default/binary_www_old/fes/spoluprace/s-absolventy/kratky-prezetace.pdf (accessed on 5 November 2019).

Loehken Sylvia. 2016. The Power of Personality: How Introverts and Extroverts Can Combine to Amazing Effect. Hamburk: John Murray Learning Publishing. 
McNamara James. P. 2003, September. The Neutral Project Manager. Paper presented at PMI® Global Congress 2003-North America, Baltimore, MD. Newtown Square, PA: Project Management Institute.

Marik Vladimir et al. 2016. Průmysl 4.0: výzva pro Českou republiku. Praha: Management Press.

Middleton Scott. 2017. 3 ways AI will change project management for the better. Available online: https:/www.atlassian.com/blog/software-teams/3-ways-ai-will-change-project-management-better (accessed on 5 November 2019).

Misopoulos Fotios, Michaelides Roula, Salehuddin Afiq, Manthou Vicky, and Michaelides Zenon. 2018. Addressing Organisational Pressures as Drivers towards Sustainability in Manufacturing Projects and Project Management Methodologies. Sustainability: 10(6), 2098. https://doi.org/10.3390/su10062098.

Mohan Namratha. 2019. Project Management Trends of 2019: How Future-Ready Are You? Available online: https://www.saviom.com/blog/project-management-trends-2019/ (accessed on 6 November 2019).

Musienko Yuri. 2019. Project Management Trends in 2020. Available online: https://merehead.com/blog/trendsin-project-management-in-2020/ (accessed on 5 November 2019).

Newman Joanna, and Williams Nigel. 2015. What will project teams look like in 2020? Paper presented at PMI® Global Congress 2015-EMEA, London, England. Newtown Square, PA: Project Management Institute. Available online: https:/www.pmi.org/learning/library/project-teams-2020-9648 (accessed on 4 December 2019).

Pinto Jeffrey K. 2010. Project Management: Achieving Competitive Advantage. 2nd ed. Prentice Hall: Pearson Education, Inc, 490.

Project Management Institute. 2017. Project Management Job Growth and Talent Gap Report 2017-2027. Newtown Square: Project Management Institute.

Project Management Institute. 2019. Success in Disruptive Times. Available online: https://www.pmi.org//media/pmi/documents/public/pdf/learning/thought-leadership/pulse/pulse-of-the-profession-2018.pdf (accessed on 5 November 2019).

Rahman Haji, Nouman Shafique Muhammad, and Rashid Ammar. 2018. Project Success in the Eyes of Project Management Information System and Project Team Members. Abasyn Journal Of Social Sciences: 11.

Rastogi Ankit. 2019. Project Management 2019 trends. Available online: https:/www.greycampus.com/blog/project-management/top-project-management-trends-in-2019 (accessed on 5 November 2019).

Rinne April. 2017. What Exactly is the Sharing Economy? World Economic Forum. Available online: https:/www.weforum.org/agenda/2017/12/when-is-sharing-not-really-sharing/ (accessed on 15 October 2019).

Rose Margaret. 2016. Platform economy. Available online: https://searchcio.techtarget.com/definition/platformeconomy. (accessed on 15 October 2019).

Sayers Janet. 2017. Managing Diversity. Bookbook.com.

Schroeder Amber. N., Bricka Traci M., and Whitaker Julia Hylton. 2019. Work design in a digitized gig economy. Human Resource Management Review: in print. https://doi.org/10.1016/j.hrmr.2019.100692.

Silvius Gilbert, Schipper Ron, Planko Julia, van den Brink Jasper, and Köhler Adri. 2012. Sustainability in Project Management. Farnham: Gower Publishing Limited.

Zheng Junwei, Wu Guangdong, Xie Hongtao, and Xu Hui. 2017. Ambidextrous Leadership and SustainabilityBased Project Performance: The Role of Project Culture. Sustainability: 9(12), 2336. https://doi.org/10.3390/su9122336. 